\title{
AN ANALYSIS OF PERMANENT MAGNET EDDY CURRENT
}

\section{BRAKING SYSTEM}

\section{SHIVASHANKAR. R, Dr. G. V. NAVEEN PRAKASH, ARUN C. DIXIT. U,}

GURURAJA. S \& VISMAY. K. G

Department of Mechanical Engineering, Vidyavardhaka College of Engineering, Mysuru, Karnataka, India

In the operation of any machinery the most primary safety system is the braking system. The most basic designs of the braking system involve the conversion of kinetic energy to heat energy by friction. This is accomplished by friction between two rubbing surfaces. These brakes pose several problems i.e. significant wear, fading, complex and slow actuation etc. This paper is an attempt to solve these problems, where a contactless magnetic brake has been developed by using a metals disc which will conduct eddy currents generated by magnets and the same is analyzed by using COMSOL software.
\end{abstract}

KEYWORDS: COMSOL, Eddy Current Brake \& Permanent Magnet

Received: Apr 22, 2019; Accepted: May 13, 2019; Published: Jun 14, 2019; Paper Id.: IJMPERDAUG20193

\section{INTRODUCTION}

The developed brake is wear-free, less-sensitive to temperature than friction brakes, has fast and simple actuation, and has a reduced sensitivity to wheel lock. This is achieved by the generation of braking torque by a magnetic field across a moving conductor which creates a perpendicular magnetic field by induced eddy currents. Contactless brakes can be applied to any machinery like automobiles, locomotives, roller coasters, hydraulic and turbo machinery, machine tools, elevators, etc. The wide range applicability of these brakes strongly implies the effectiveness and ease of operation. The braking force can be adjusted to control higher torque loads by increasing number of magnets and surface area of magnet. This gives flexibility of operation of the system and makes it reliable even in changing loading patterns. There are two ways to induce eddy current in the rotor; they are strong permanent magnet and electromagnet. Electromagnets are DC type which is powered by battery. They have faster electrical actuation with lower losses. But in case of battery discharge electromagnets pose significant problems and are not reliable. So here, an experimental and software study of permanent magnet eddy current braking system is performed to find out the practical limits of ECBS. Analysis was done by varying various experimental parameters. Simulation will be done using COMSOL Multiphysics ${ }^{\circledR}$ software and suitable results and conclusions will be obtained. Here, in our study we are using two types of permanent magnets (NdFeB and Ferrite). Copper, and Aluminum 6061 are used as disc materials. The air gap between disc and permanent magnet will be adjusted by threaded screw mechanism. To rotate and control the speed of the disc, an AC motor with rpm regulator is used. To apply braking torque, lever mechanism is used with a changeable permanent magnet attached at its end. The drawbacks of the conventional braking system can be overcome by eddy current braking system. Contactless brakes can be applied to machineries including electric vehicles, passenger trains, bullet trains, roller coasters, hydraulic and turbo machinery, machine tools, elevators, etc. The wide range applicability of these brakes strongly 
implies the effectiveness and ease of operation. Our project aims at optimizing the performance of ECBS by determining superior working conditions. With increasing R\&D on ECBs in International level, the ECB may evolve as a major alternative to conventional friction braking system in the not so distant future. The term eddy current comes from analogous currents seen in water in fluid dynamics, causing localized areas of turbulence known as eddies giving rise to persistent vortices. Somewhat analogously, eddy currents can take time to build up and can persist for very short times in conductors due to their inductance. The first person to observe eddy currents was François Arago (1786-1853), the 25th Prime Minister of France, who was also a mathematician, physicist and astronomer. In 1824 he observed what has been called rotatory magnetism, and that most conductive bodies could be magnetized; these discoveries were completed and explained by Michael Faraday (1791-1867). In 1834, Heinrich Lenz stated Lenz's law, which says that the direction of induced current flow in an object will be such that its magnetic field will oppose the change of magnetic flux that caused the current flow. Eddy currents produce a secondary field that cancels a part of the external field and causes some of the external flux to avoid the conductor. French physicist Léon Foucault (1819-1868) is credited with having discovered eddy currents. In September, 1855, he discovered that the force required for the rotation of a copper disc becomes greater when it is made to rotate with its rim between the poles of a magnet, the disc at the same time becoming heated by the eddy current induced in the metal. The first use of eddy current for nondestructive testing occurred in 1879 when David E. Hughes used the principles to conduct metallurgical sorting tests. Applications of this braking system is very wide, which includes Electromagnetic braking, Repulsive effects and levitation, Identification of metals, Vibration and position sensing, Structural testing, Skin effects, Rock Climbing Auto Belays, Zip Line Brakes, Free Fall Devices, Metal detectors, Conductivity meters for non-magnetic metals, Eddy current adjustable-speed drives, Eddy-current testing, Electric meters (Electromechanical Induction Meters), Induction heating, Proximity sensor (Displacement sensors), Vending machines (detection of coins), Coating Thickness Measurements, Sheet Resistance Measurement, Eddy current separator for metal separation, Mechanical speedometers, Safety Hazard and defect detection application.

\section{Principle of Operation of Brake}

Eddy current brakes use the drag force created by eddy currents as a brake to slow or stop moving objects. Since there is no contact with a brake shoe or drum, there is no mechanical wear. However, an eddy current brake cannot provide a "holding" torque and so may be used in combination with mechanical brakes, for example, on overhead cranes. Another application is on some roller coasters, where heavy copper plates extending from the car are moved between pairs of very strong permanent magnets. Electrical resistance within the plates causes a dragging effect analogous to friction, which dissipates the kinetic energy of the car. The same technique is used in electromagnetic brakes in railroad cars and to quickly stop the blades in power tools such as circular saws. Using electromagnets, as opposed to permanent magnets, the strength of the magnetic field can be adjusted and so the magnitude of braking effect changed. Eddy current braking technology is a useful tool in a growing world. Innovations in exercise equipment, industrial tools, entertainment, roller coasters, and transportation are just the tip of the iceberg. As new advancements are being produced a safer and more efficient world is being born. The eddy current brake can be applied to many things in our everyday world, even more than we might expect. Take notice of everyday applications of this high tech innovation. The risk management improvements and economic advantages that accompany the eddy current brake has made it a popular choice among engineers when developing new technologies or improving the old. This intricate network of magnets is used more commonly than you might think. Recognizable uses for eddy currents 
are all around us. They exist in the home and in the work place.

\section{METHODOLOGY AND WORKING PRINCIPLE OF THE DEVELOPED SYSTEM}

Initially, the rotor disc is mounted on a mild steel shaft which is coupled to single phase AC motor with the help of M-type pulley and V-belt. The speed of the disc is varied with the help of 3 channel rpm regulator. By the application of brake lever the permanent magnet is brought near the rotating disc with very small air gap. Then eddy currents are induced in the rotor due to varying magnetic flux and these eddy currents oppose the rotation of the disc by the principle of Lenz law and hence within a few seconds the disc comes to rest. The air gap can be adjusted by threaded screw mechanism. Aluminum 6061 and Copper discs have been used. Neodymium Iron Boron (NdFeB) and Ferrite permanent magnets have been used. Disc rpm is varied using pulleys of ratio 1:2 and 1:5 along with 3 channel rpm regulator. So, we are able to vary different parameters of the permanent magnet eddy current braking system (ECBS) and come to suitable results and conclusions based on the experimental analysis and simulations using COMSOL software. The detailed considerations and specifications are in Table 1. Components include Single Phase Ac Motor (1), Aluminum Disc (2), Bearing Block (3), Mild Steel Shaft (4), Ndfeb Permanent Magnet (5), M-Type Pulley (6), Rpm Regulator (7), Supporting Stand (8), as shown in figure 1.
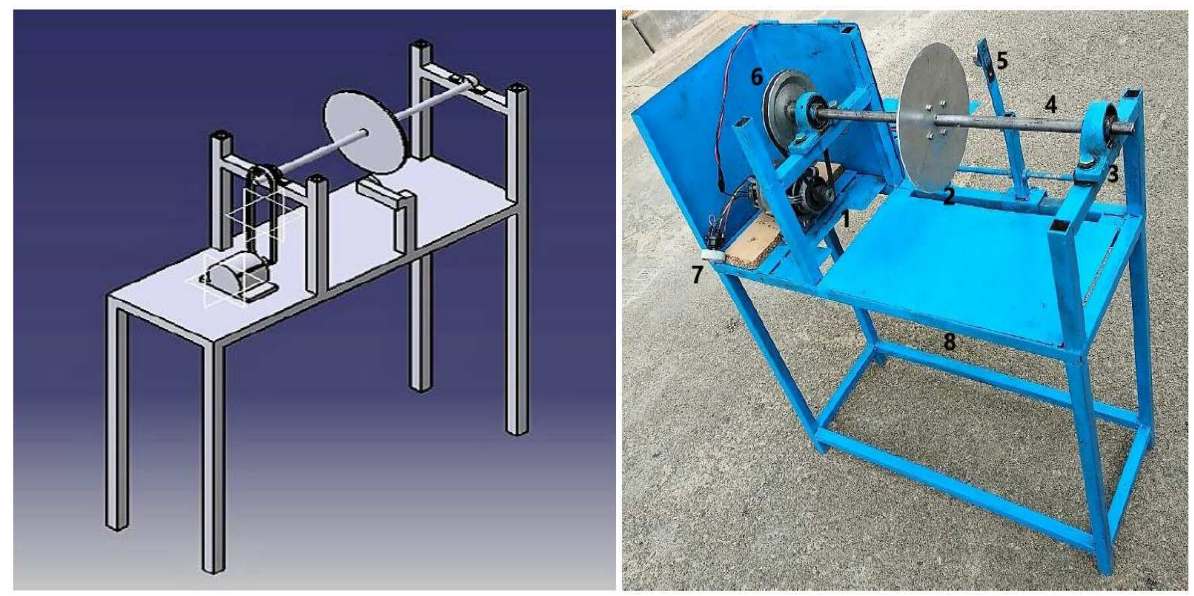

Figure 1: CAD Model of the Setup and Developed Experimental Setup

\section{Design Considerations and Specifications}

Table 1: Design Consideration and Specifications

\begin{tabular}{|c|c|c|}
\hline Components & Considerations & Specifications \\
\hline Motor & $\begin{array}{l}\text { Motor is chosen based on the load condition. } \\
\text { Our project requires lower load conditions, so } \\
\text { we have selected motor which are used in } \\
\text { sewing machine }\end{array}$ & $\begin{array}{l}\text { Type: AC Single phase } \\
\text { Speed: } 6500 \mathrm{rpm} \\
\text { Horse power: } 1 \mathrm{HP} \\
\text { Voltage: } 220 \text { volts }\end{array}$ \\
\hline Rotor Disc & $\begin{array}{l}\text { According to research journal copper, } \\
\text { Aluminum } 7075 \text {, Aluminum } 6061 \text { and Zinc are } \\
\text { the best materials for usage in ECBS. } \\
\text { We chose copper and aluminum } 6061 \text { as disc } \\
\text { materials for their better properties. } \\
\text { We considered the dimensions of brake disc of } \\
\text { an automobile to for rotor material. }\end{array}$ & $\begin{array}{l}\text { Copper disc: } \\
\text { Density: } 8.96 \mathrm{gm} / \mathrm{cm} 3 \\
\text { Disc diameter: } 200 \mathrm{~mm} \\
\text { Weight: } 1.41 \mathrm{~kg} \\
\text { Thickness: } 3 \mathrm{~mm} \\
\text { Aluminum } 6061 \text { disc: } \\
\text { Density: } 2.7 \mathrm{gm} / \mathrm{cm} 3 \\
\text { Disc diameter: } 200 \mathrm{~mm} \\
\text { Weight: } 0.424 \mathrm{~kg} \\
\text { Thickness: } 3 \mathrm{~mm}\end{array}$ \\
\hline
\end{tabular}




\begin{tabular}{|c|c|c|}
\hline \multicolumn{3}{|c|}{ Table 1: Contd., } \\
\hline $\begin{array}{l}\text { Permanent } \\
\text { Magnets }\end{array}$ & $\begin{array}{l}\text { There are } 4 \text { types of permanent magnets } \\
\text { available } \\
\text { 1) Neodymium iron boron }(\mathrm{NdFeB}) \\
\text { 2) Samarium cobalt ( } \mathrm{SmCo}) \\
\text { 3) Aluminum nickel cobalt (AlNiCo) } \\
\text { 4) Ceramic (Ferrite) } \\
\text { After market survey, we got only } 2 \text { types } \\
\text { Neodymium iron boron magnet and ferrite } \\
\text { magnet }\end{array}$ & $\begin{array}{l}\text { Type 1: NdFeB Disc magnet } \\
\text { Diameter: } 36 \mathrm{~mm} \\
\text { Thickness: } 10 \mathrm{~mm} \\
\text { Quantity: } 1 \\
\text { Type 2: Ferrite Disc magnet } \\
\text { Diameter: } 36 \mathrm{~mm} \\
\text { Thickness: } 10 \mathrm{~mm} \\
\text { Quantity: } 2\end{array}$ \\
\hline Belt drive & $\begin{array}{l}\text { Some of the commercially available belt types } \\
\text { are flat, v, round etc. } \\
\text { V-belt are used in heavy load conditions, } \\
\text { excellent grip, large power transmission lengths } \\
\text { and higher rpm applications. So we chose V- } \\
\text { belt. } \\
\text { To vary the rpm range, we have used } 2 \text { pulleys } \\
\text { of different ratios. }\end{array}$ & $\begin{array}{l}\text { Belt type: V-belt M type } \\
\text { Centre distance: } 150 \mathrm{~mm} \\
\text { Pulley : } \\
\text { Diameter: } 16 \mathrm{~mm} \\
\text { Pulley 1: } \\
\text { Ratio: } 1: 2 \\
\text { Pulley 2: } \\
\text { Ratio: } 1: 5\end{array}$ \\
\hline Shaft & $\begin{array}{l}\text { Based on torque, speed, power transmitted and } \\
\text { load condition the calculated shaft diameter is } \\
16 \mathrm{~mm} \text { and length is } 400 \mathrm{~mm} \text {. } \\
\text { Mild steel is one of the preferable materials for } \\
\text { shaft. So we have selected it. }\end{array}$ & $\begin{array}{l}\text { Shaft material: Mild steel } \\
\text { Length between support stand: } 400 \\
\text { mm } \\
\text { Overall length: } 500 \mathrm{~mm} \\
\text { Shaft diameter: } 16 \mathrm{~mm}\end{array}$ \\
\hline Frame & It is used as support structure. & $\begin{array}{l}\text { Metal used: Mild steel } \\
\text { Dimensions: }(25 * 25) \text { Square tube }\end{array}$ \\
\hline Bearing Block & $\begin{array}{l}\text { Used to withstand the load and absorb } \\
\text { vibrations. }\end{array}$ & $\begin{array}{l}\text { Type: Journal bearing } \\
\text { Inner diameter: } 15 \mathrm{~mm}\end{array}$ \\
\hline
\end{tabular}

\section{Testing and Performance}

\section{Experimental Analysis}

The CAD model of experimental setup was done in CATIA V5 (Figure 1) and fabricated experimental setup (Figure 1) is designed and fabricated in such a way as to resemble a high speed application. Motor used is 1 HP Single phase AC Motor with maximum speed of $6500 \mathrm{rpm}$ directly plugged to switch board. To reduce the motor speed we used two different $\mathrm{M}$ type pulleys (Table 1) of ratios 1:2 and 1:5 with V-belts of suitable lengths. Speed is varied using 3 channel rpm regulator. Two types of permanent magnets (NdFeB and Ferrite) are used. The Disc materials varied are Al 6061 and Copper. Experimentation is conducted by varying certain parameters like, Air gap: 5mm tolerance was given to prevent colliding of disc and magnet. So air gaps of $6 \mathrm{~mm}$ and $10 \mathrm{~mm}$ were selected. Rpm range: we used 3 channel rpm regulator and pulleys of ratios 1:2 and 1:5. Copper due to its high density and weight couldn't attain the speed of A16061. Experimentation was done for the below speed ranges. For 1:5 ratio pulley, for Al6061- 1500rpm1800rpm-2100rpm and for Copper - 1500rpm-1750rpm-1900rpm. For 1:2 ratio pulley: for Al6061 - 3000rpm3400rpm-3800rpm and for Copper - 3000rpm-3200rpm-3400rpm. Initially, time required to stop the rotating disc without magnet was recorded and the same was done with magnet. The procedure was repeated was $\mathrm{Al} 6061$, and $\mathrm{Cu}$ discs, NdFeB and Ferrite magnets, $6 \mathrm{~mm}$ and $10 \mathrm{~mm}$ air gaps. The experimental values are tabulated and graphs are plotted and analyzed as below.

\section{Analysis and Discussion of Al 6061 Disc}

Al 6061 being very light metal higher speeds were attained compared to copper. The time required by Al 6061 disc to stop without magnet and with $\mathrm{NdFeB}$, Ferrite magnets against air gaps of $6 \mathrm{~mm}$ and 10mm are tabulated in Table 2. From Table 2 we can notice that the reduction percentage in time gradually increases with increase in rpm 
irrespective of change in magnet and air gap. But we notice the increase in stopping time in Ferrite magnet and $10 \mathrm{~mm}$ air gap relative to $\mathrm{NdFeB}$ magnet and $6 \mathrm{~mm}$ air gap respectfully. Maximum reduction \% in time of $97.37 \%$ is achieved in 3800rpm when NdFeB magnet is used against $6 \mathrm{~mm}$ air gap. Minimum reduction $\%$ in time of $22.06 \%$ is achieved in 1500rpm when Ferrite magnet is used against 10mm air gap. The Graphs 1, 2, 3 and 4 shows stopping time in seconds of Al6061 disc plotted in Y-axis against speed range in rpm in X-axis. The yellow and blue curves indicate stopping time obtained when 1:5 ratio pulley was used for conditions like without magnet and with magnet respectfully. The dark blue and pink curves indicate stopping time obtained when 1:2 ratio pulley was used for conditions like without magnet and with magnet respectfully. In Graph 1, yellow curve has points 15.41, 20.18 and 26.43 seconds. Blue curve has points 1.64, 2.03 and 2.44 seconds. Dark blue curve has points 18.41, 29.87 and 52.48 seconds. Pink curve has points $0.94,1.26$ and 1.38 seconds. In Graph 2, yellow curve has points 15.41, 20.18 and 26.43 seconds. Blue curve has points 1.92, 2.87 and 3.26 seconds. Dark blue curve has points 18.41, 29.87 and 52.48 seconds. Pink curve has points 1.91, 2.47 and 3.09 seconds. In Graph 3, yellow curve has points 15.41, 20.18 and 26.43 seconds. Blue curve has points 10.35, 12.48 and 14.72 seconds. Dark blue curve has points 18.41, 29.87 and 52.48 seconds. Pink curve has points 8.79, 13.72 and 20.03 seconds. In Graph 4, yellow curve has points 15.41, 20.18 and 26.43 seconds. Blue curve has points 12.01, 14.93 and 19.28 seconds. Dark blue curve has points 18.41, 29.87 and 52.48 seconds. Pink curve has points $11.83,18.34$ and 27.57 seconds

Table 2: Table of Result for Al 6061 Disc

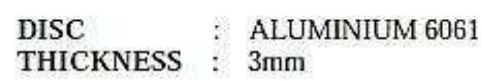

\begin{tabular}{|c|c|c|c|c|c|}
\hline \multirow{3}{*}{$\begin{array}{l}\text { Speed } \\
\text { (in rpm) }\end{array}$} & \multirow{3}{*}{ Study Type } & \multicolumn{4}{|c|}{ Stopping Time (in sec) } \\
\hline & & \multicolumn{2}{|c|}{ Magnet used : Neodymium } & \multicolumn{2}{|c|}{ Magnet used : Ferrite } \\
\hline & & Air Gap : $6 \mathrm{~mm}$ & Air Gap : $10 \mathrm{~mm}$ & Air Gap : $6 \mathrm{~mm}$ & Air Gap : $10 \mathrm{~mm}$ \\
\hline \multirow{3}{*}{1500} & Without Magnet & 15.41 & 15.41 & 15.41 & 15.41 \\
\hline & With Magnet & 1.64 & 1.92 & 10.35 & 12.01 \\
\hline & Reduction (in \%) & 89.36 & 87.54 & 32.84 & 22.06 \\
\hline \multirow{3}{*}{1800} & Without Magnet & 20.18 & 20.18 & 20.18 & 20.18 \\
\hline & With Magnet & 2.03 & 2.87 & 12.48 & 14.93 \\
\hline & Reduction (in \%) & 89.94 & 85.78 & 38.16 & 26.02 \\
\hline \multirow{3}{*}{2100} & Without Magnet & 26.43 & 26.43 & 26.43 & 26.43 \\
\hline & With Magnet & 2.44 & 3.26 & 14.72 & 19.28 \\
\hline & Reduction (in \%) & 90.77 & 87.67 & 44.31 & 27.05 \\
\hline \multirow{3}{*}{3000} & Without Magnet & 18.41 & 18.41 & 18.41 & 18.41 \\
\hline & With Magnet & 0.94 & 1.91 & 8.79 & 11.83 \\
\hline & Reduction (in \%) & 94.89 & 89.63 & 52.25 & 35.74 \\
\hline \multirow{3}{*}{3400} & Without Magnet & 29.87 & 29.87 & 29.87 & 29.87 \\
\hline & With Magnet & 1.26 & 2.47 & 13.72 & 18.34 \\
\hline & Reduction (in \%) & 95.78 & 91.73 & 54.07 & 38.60 \\
\hline \multirow{3}{*}{3800} & Without Magnet & 52.48 & 52.48 & 52.48 & 52.48 \\
\hline & With Magnet & 1.38 & 3.09 & 20.03 & 27.57 \\
\hline & Reduction (in \%) & 97.37 & 94.11 & 61.83 & 47.47 \\
\hline
\end{tabular}


Al6061, 3mm, ndfeb, $6 \mathrm{~mm}$

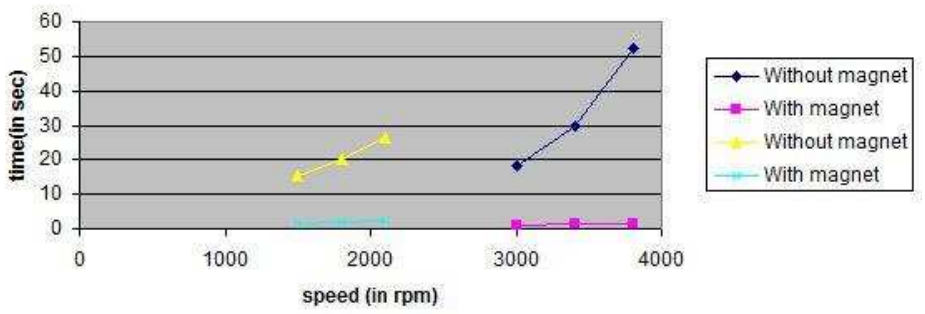

Graph 1: Al 6061 - 3mm dia- NdFeB Magnet -6mm Air Gap

Al6061, 3mm, ndfeb, $10 \mathrm{~mm}$

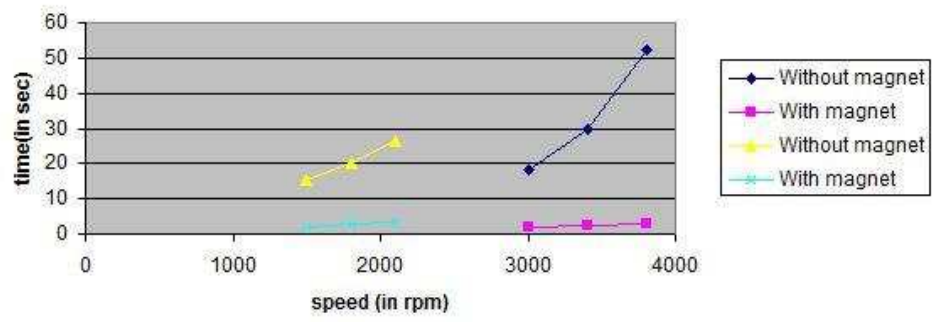

Graph 2: Al 6061 - 3mm dia- NdFeB Magnet -10mm Air Gap

Al6061, 3mm, Ferrite, $6 \mathrm{~mm}$

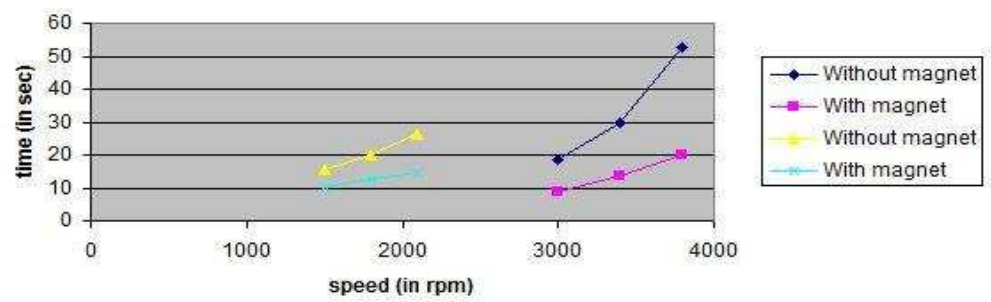

Graph 3: Al 6061 - 3mm dia- Ferrite Magnet -6mm Air Gap

Al6061, 3mm, Ferrite, $10 \mathrm{~mm}$

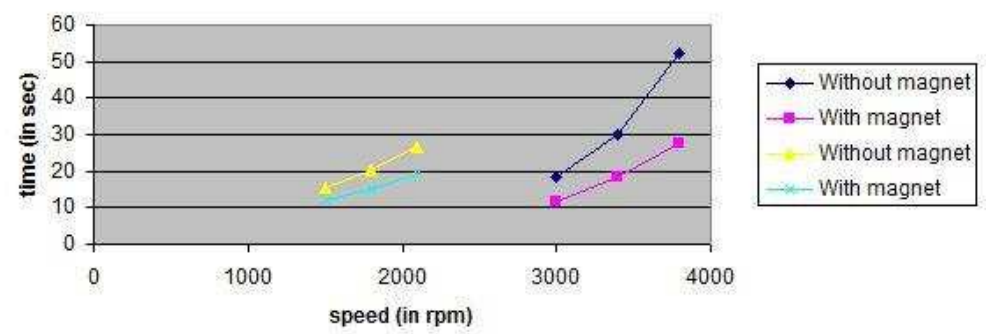

Graph 4: Al 6061 - 3mm dia- Ferrite Magnet -10mm Air Gap 


\section{Aluminum 6061 - 3mm dia- NdFeB magnet - 6mm Air Gap}

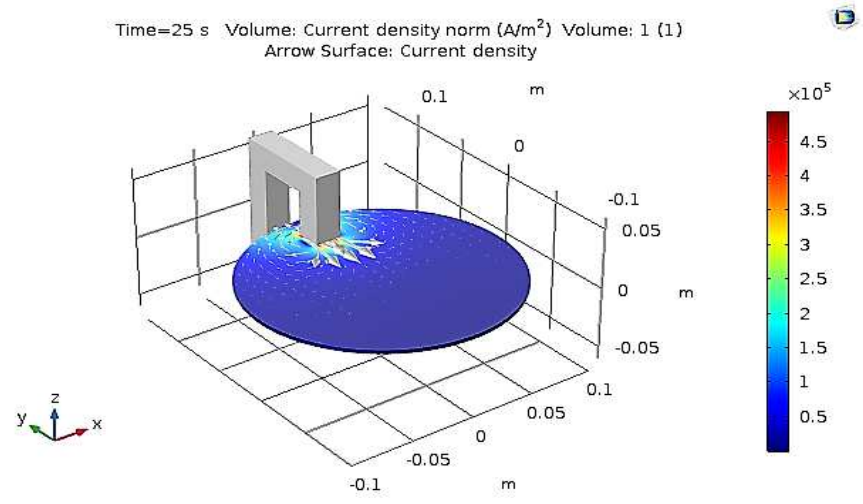

Figure 2: Eddy Current Density Plot for Al6061-NdFeB Magnet-6mm Air Gap

The magnitude of Eddy current density developed is around $4.5 \times 10^{5} \mathrm{~A} / \mathrm{m}^{2}$. Figure 2 also shows the direction of eddy currents induced in the rotating disc which are away from the magnet.

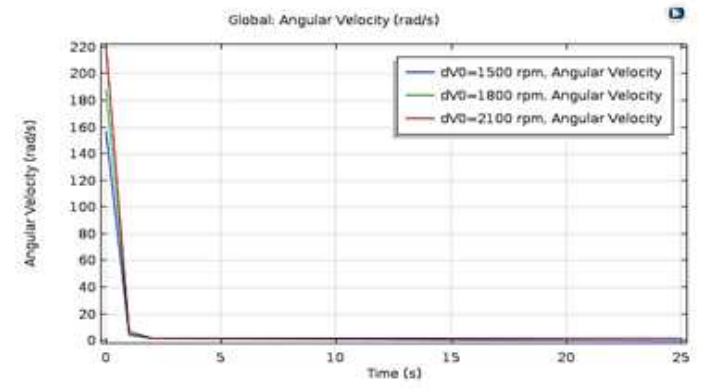

Graph 5

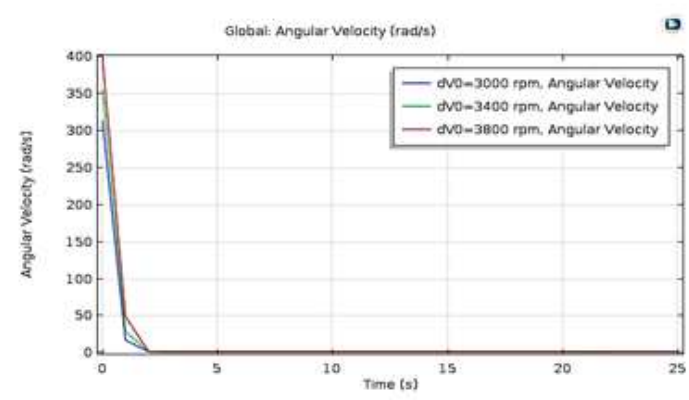

Graph 6

Graph 5 represents deceleration plot for Al6061- NdFeB magnet - 6mm air gap - 1:5 ratio pulley, also from graph 5, we observe that stopping time obtained from simulation for curves 1500rpm, $1800 \mathrm{rpm}$ and $2100 \mathrm{rpm}$ are close to $1.5,2$ and 2.5 seconds respectively. Graph 6 represents deceleration plot for A16061-NdFeB magnet-6mm air gap1:2 ratio pulleys also from Graph 6, we observe that stopping time obtained from simulation for curves $3000 \mathrm{rpm}$, 3400 rpm and $3800 \mathrm{rpm}$ are close to $1,1.5$ and 2 seconds respectively.

\section{Aluminum 6061 - 3mm dia- NdFeB Magnet - 10mm Air Gap}

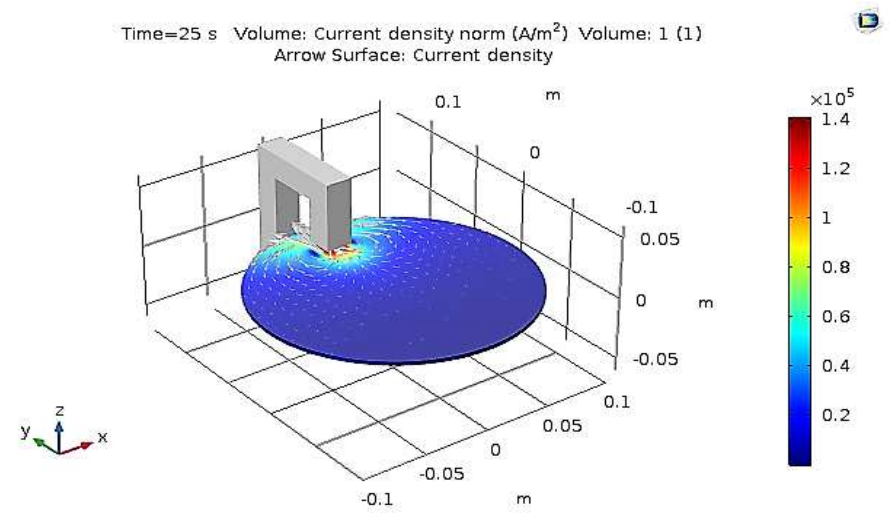

Figure 3: Eddy Current Density Plot for Al6061-NdFeB Magnet-10mm Air Gap 
The magnitude of Eddy current density developed is around $1.4 \times 10^{5} \mathrm{~A} / \mathrm{m}^{2}$. Figure 3 also shows the direction of eddy currents induced in the rotating disc which are towards the magnet.

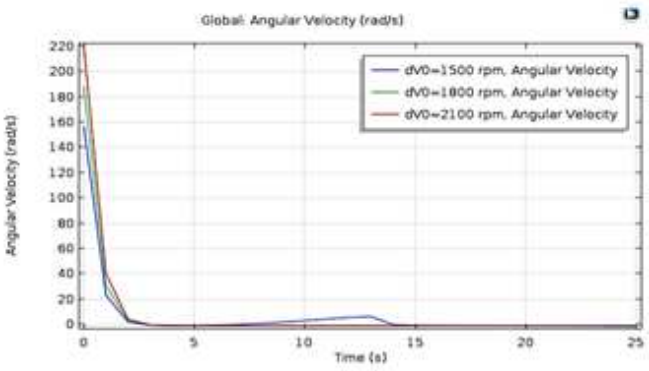

Graph 7

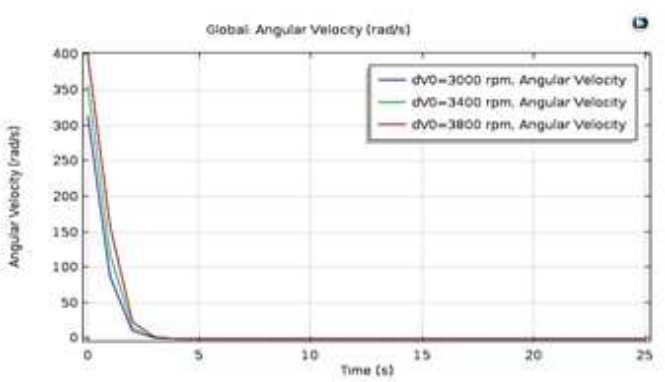

Graph 8

Graph 7 represents deceleration plot for A16061-NdFeB magnet-10mm air gap-1:5 ratio pulley also from Graph 7, we observe that stopping time obtained from simulation for curves 1500rpm, $1800 \mathrm{rpm}$ and $2100 \mathrm{rpm}$ are close to 2, 3 and 3.5 seconds respectively. Graph 8 represents deceleration plot for A16061-NdFeB magnet-10mm air gap-1:2 ratio pulley also from Graph 8, we observe that stopping time obtained from simulation for curves 3000rpm, $3400 \mathrm{rpm}$ and $3800 \mathrm{rpm}$ are close to 2, 2.5 and 3 seconds respectively.

\section{Aluminum 6061 - 3mm dia- Ferrite Magnet - 6mm Air Gap}

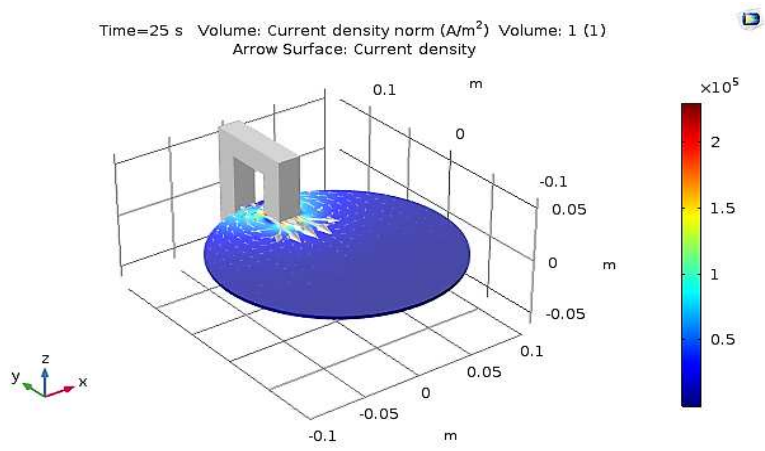

Figure 4: Eddy Current Density Plot for Al6061-Ferrite Magnet-6mm Air Gap

The magnitude of Eddy current density developed is around $2.0 \times 10^{5} \mathrm{~A} / \mathrm{m}^{2}$. Figure 4 also shows the direction of eddy currents induced in the rotating disc which are away from the magnet.

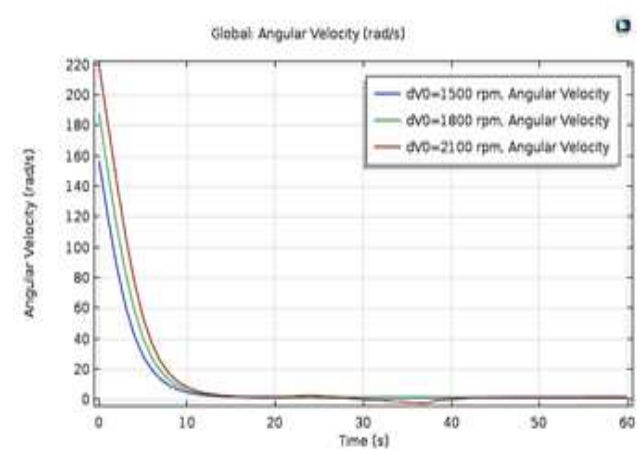

Graph 9

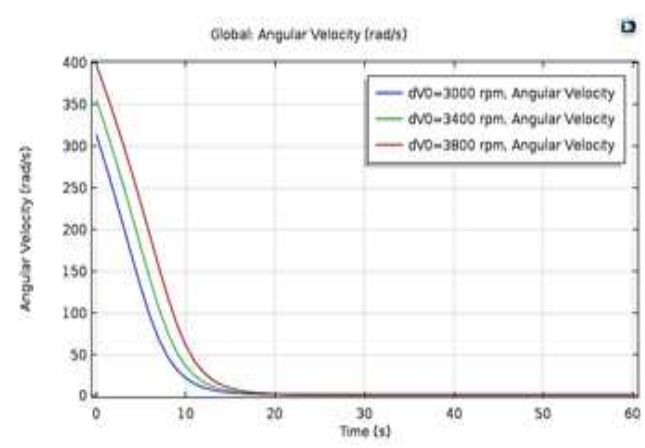

Graph 10 
Graph 9 represents deceleration plot for Al6061-Ferrite magnet-6mm air gap-1:5 ratio pulley also from Graph 9, we observe that stopping time obtained from simulation for curves $1500 \mathrm{rpm}, 1800 \mathrm{rpm}$ and $2100 \mathrm{rpm}$ are close to 10.5, 12.5 and 15 seconds respectively. Graph 10 represents deceleration plot for Al6061-Ferrite magnet-6mm air gap1:2 ratio pulley also from Graph 10, we observe that stopping time obtained from simulation for curves $3000 \mathrm{rpm}$, 3400 rpm and $3800 \mathrm{rpm}$ are close to 12,15 and 18 seconds respectively.

\section{Aluminum 6061 - 3mm dia- Ferrite Magnet - 10mm Air Gap}

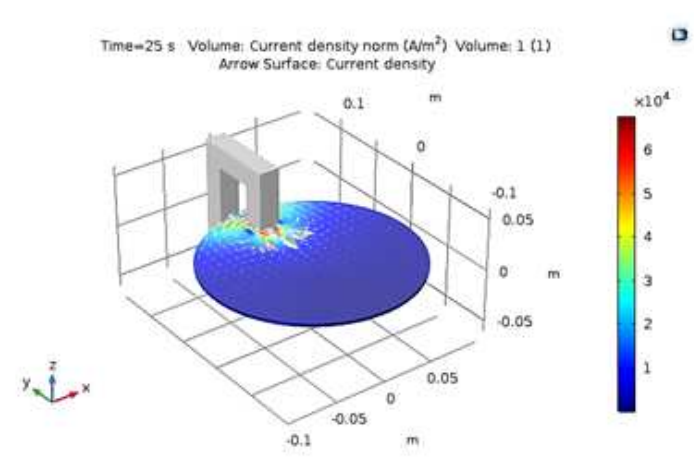

Figure 5

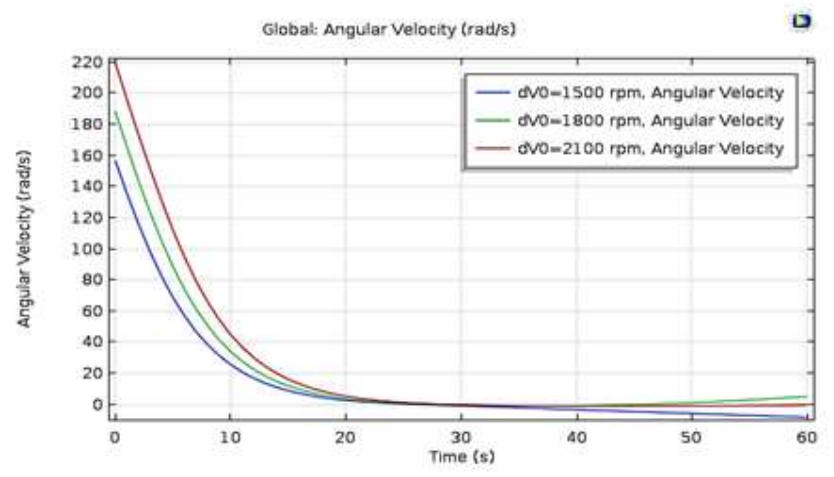

Graph 11

Figure 5 shows eddy current density plot for Al6061-Ferrite magnet-10mm air gap. The magnitude of Eddy current density developed is around $6.0 \times 10^{4} \mathrm{~A} / \mathrm{m}^{2}$. Figure 5 also shows the direction of eddy currents induced in the rotating disc which are away from the magnet. Graph 11represents deceleration plot for Al6061-Ferrite magnet-10mm air gap-1:5 ratio pulley also from Graph 11, we observe that stopping time obtained from simulation for curves 1500rpm, $1800 \mathrm{rpm}$ and $2100 \mathrm{rpm}$ are close to 17,20 and 22 seconds respectively.

\section{Analysis and Discussion of Copper Disc}

Table 3: Table of Result for Cu Disc

\begin{tabular}{|c|c|c|c|c|c|}
\hline $\begin{array}{l}\text { DISC } \\
\text { THICKNESS }\end{array}$ & $\begin{aligned} & : \text { COPPER } \\
\text { SSS } & : 3 \mathrm{~mm}\end{aligned}$ & & & & \\
\hline \multirow{3}{*}{$\begin{array}{c}\text { Speed } \\
\text { (in rpm) }\end{array}$} & \multirow{3}{*}{ Study Type } & \multicolumn{4}{|c|}{ Stopping Time (in sec) } \\
\hline & & \multicolumn{2}{|c|}{ Magnet used : Neodymium } & \multicolumn{2}{|c|}{ Magnet used : Ferrite } \\
\hline & & Air Gap : $6 \mathrm{~mm}$ & Air Gap : $10 \mathrm{~mm}$ & Air Gap : $6 \mathrm{~mm}$ & Air Gap : $10 \mathrm{~mm}$ \\
\hline \multirow{3}{*}{1500} & Without Magnet & 22.91 & 22.91 & 22.91 & 22.91 \\
\hline & With Magnet & 3.87 & 5.38 & 9.43 & 13.21 \\
\hline & Reduction (in \%) & 83.11 & 76.52 & 58.84 & 42.34 \\
\hline \multirow{3}{*}{1750} & Without Magnet & 24.98 & 24.98 & 24.98 & 24.98 \\
\hline & With Magnet & 4.96 & 6.49 & 11.75 & 15.06 \\
\hline & Reduction (in \%) & 80.14 & 74.02 & 52.96 & 39.71 \\
\hline \multirow{3}{*}{1900} & Without Magnet & 29.83 & 29.83 & 29.83 & 29.83 \\
\hline & With Magnet & 5.47 & 7.74 & 16.27 & 19.89 \\
\hline & Reduction (in \%) & 81.66 & 74.05 & 45.46 & 33.32 \\
\hline \multirow{3}{*}{3000} & Without Magnet & 52.88 & 52.88 & 52.88 & 52.88 \\
\hline & With Magnet & 3.02 & 11.88 & 25.78 & 40.50 \\
\hline & Reduction (in \%) & 94.29 & 77.53 & 51.25 & 23.41 \\
\hline \multirow{3}{*}{3200} & Without Magnet & 54.21 & 54.21 & 54.21 & 54.21 \\
\hline & With Magnet & 3.27 & 12.08 & 29.27 & 43.28 \\
\hline & Reduction (in \%) & 93.97 & 77.72 & 46.01 & 20.16 \\
\hline \multirow{3}{*}{3400} & Without Magnet & 57.97 & 57.97 & 57.97 & 57.97 \\
\hline & With Magnet & 3.61 & 12.16 & 35.35 & 48.37 \\
\hline & Reduction (in \%) & 93.77 & 79.02 & 39.02 & 39.02 \\
\hline
\end{tabular}


Copper being a heavy metal lower speeds were attained compared to Al6061 and Al. The time taken by Copper disc to stop without magnet, and with $\mathrm{NdFeB}$, Ferrite magnets against air gaps of $6 \mathrm{~mm}$ and $10 \mathrm{~mm}$ are tabulated in Table 3. Also from table 3 we can notice that the reduction percentage in time increases and decreases randomly when different magnets and air gaps are used. The behavior of Copper disc does not form a predictable pattern. But we notice the increase in stopping time in Ferrite magnet and 10mm air gap relative to NdFeB magnet and $6 \mathrm{~mm}$ air gap respectfully. Maximum reduction \% in time of $94.29 \%$ is achieved in 3000rpm when NdFeB magnet is used against $6 \mathrm{~mm}$ air gap. Minimum reduction $\%$ in time of $20.16 \%$ is achieved in 3200rpm when Ferrite magnet is used against 10mm air gap. The Graphs 12, 13, 14 and 15 shows stopping time in seconds of Copper disc plotted in Yaxis against the speed range in rpm in X-axis. The yellow and blue curves indicate stopping time obtained when 1:5 ratio pulley was used for conditions like without magnet and with magnet respectfully. The dark blue and pink curves indicate stopping time obtained when 1:2 ratio pulley was used for conditions like without magnet and with magnet respectfully. In Graph 12, yellow curve has points 22.91, 24.98 and 29.83 seconds. Blue curve has points 3.87, 4.96 and 5.47 second. Dark blue curve has points 52.88, 54.21 and 57.97 seconds. Pink curve has points 3.02, 3.27 and 3.61 seconds. In Graph 13, yellow curve has points 22.91, 24.98 and 29.83 seconds. Blue curve has points 5.38, 6.49 and 7.74 seconds. Dark blue curve has points 52.88, 54.21 and 57.97 seconds. Pink curve has points 11.88, 12.08 and 12.16 seconds. In Graph 14, yellow curve has points 22.91, 24.98 and 29.83 seconds. Blue curve has points 9.43, 11.75 and 16.27 seconds. Dark blue curve has points 52.88, 54.21 and 57.97 seconds. Pink curve has points 25.78, 29.27 and 35.35 seconds. In Graph 14, yellow curve has points 22.91, 24.98 and 29.83 seconds. Blue curve has points 9.43, 11.75 and 16.27 seconds. Dark blue curve has points 52.88, 54.21 and 57.97 seconds. Pink curve has points $25.78,29.27$ and 35.35 seconds.

$\mathrm{Cu}, 3 \mathrm{~mm}$, ndfeb, $6 \mathrm{~mm}$

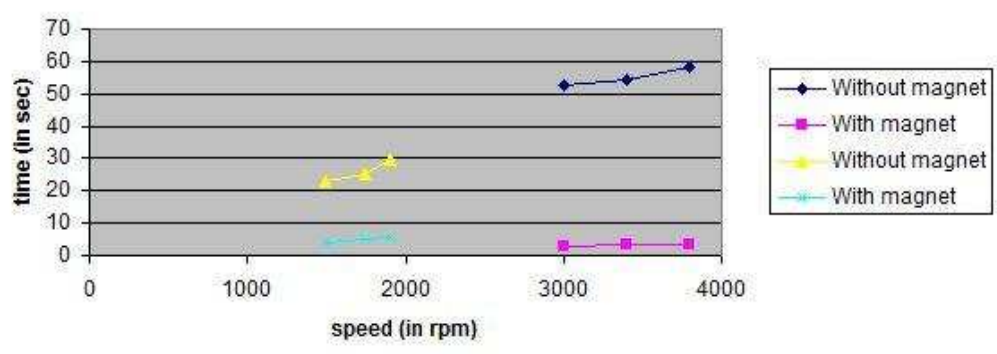

Graph 12: Copper - 3mm dia- NdFeB Magnet -6mm Air Gap

$\mathrm{Cu}, 3 \mathrm{~mm}$, ndfeb, $10 \mathrm{~mm}$

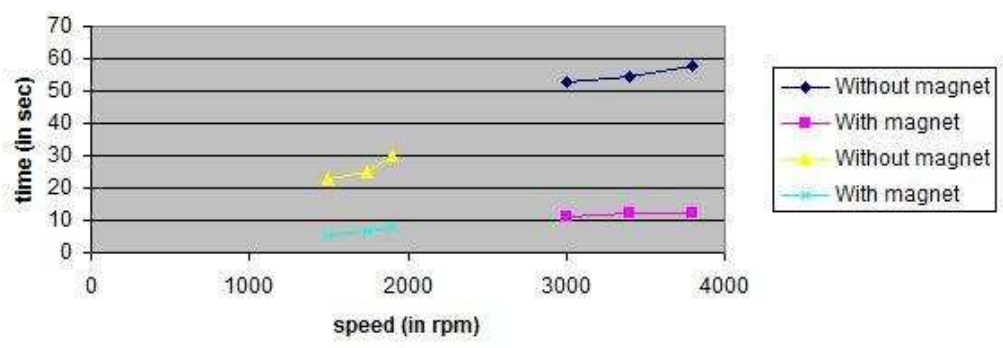

Graph 13: Copper - 3mm dia- NdFeB Magnet -10mm Air Gap 
$\mathrm{Cu}, 3 \mathrm{~mm}$, Ferrite, $6 \mathrm{~mm}$

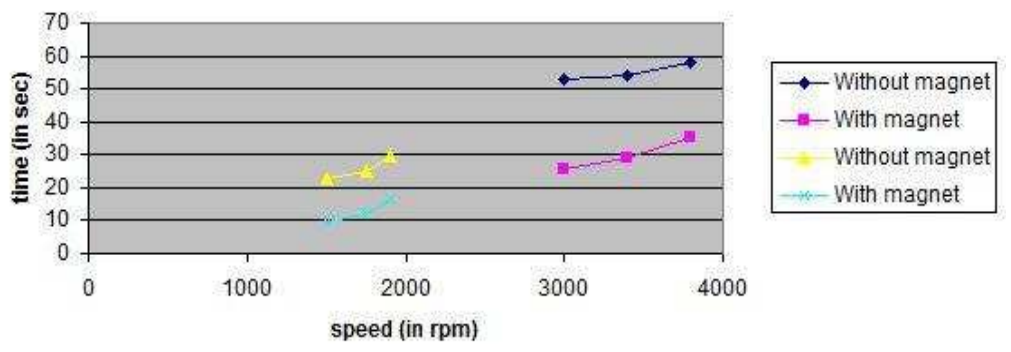

Graph 14: Copper - 3mm dia- Ferrite Magnet -6mm Air Gap

Cu, $3 \mathrm{~mm}$, Ferrite, $10 \mathrm{~mm}$

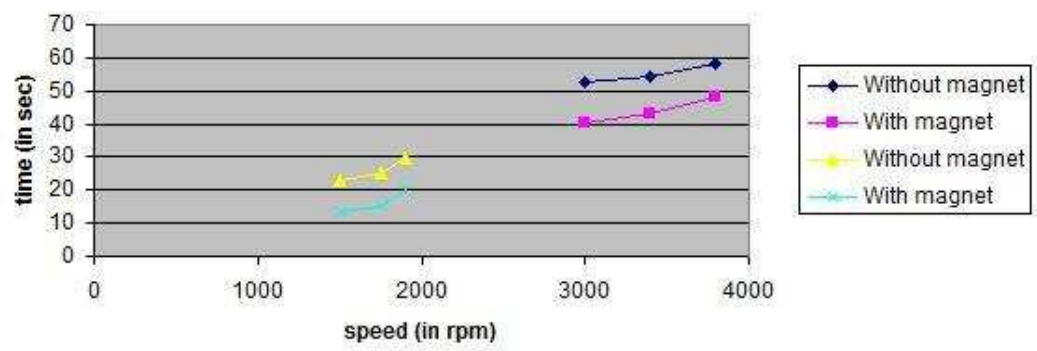

Graph 15: Copper - 3mm dia- Ferrite Magnet -10mm Air Gap

\section{Copper - 3mm dia- NdFeB Magnet - 6mm Air Gap}

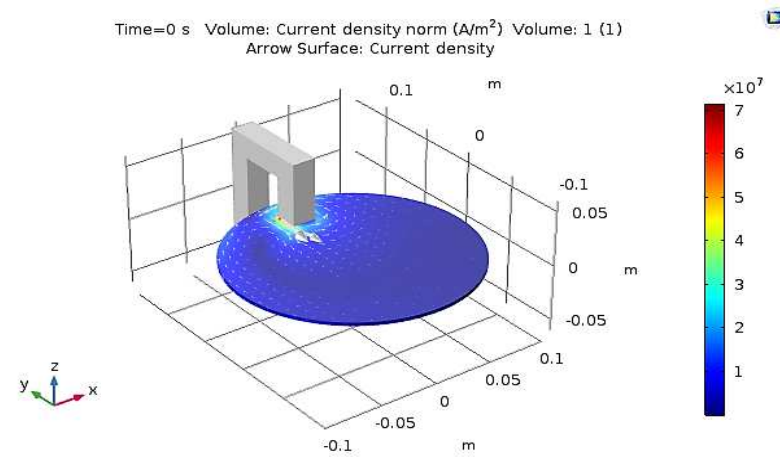

Figure 6: Eddy Current Density plot for Cu -NdFeB Magnet- 6mm Air Gap

The magnitude of Eddy current density developed is around $7 \times 10^{7} \mathrm{~A} / \mathrm{m}^{2}$. Figure 6 also shows the direction of eddy currents induced in the rotating disc which are away from the magnet.

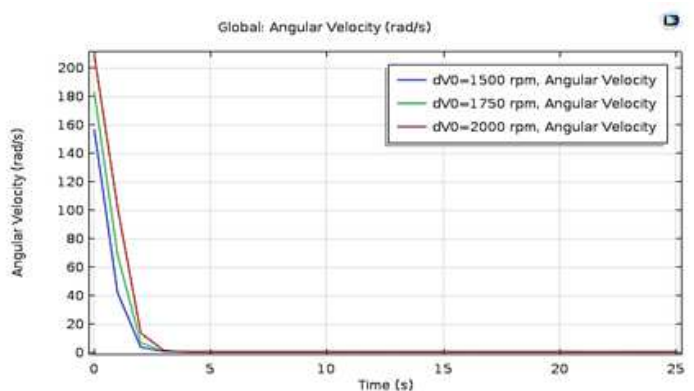

Graph 16

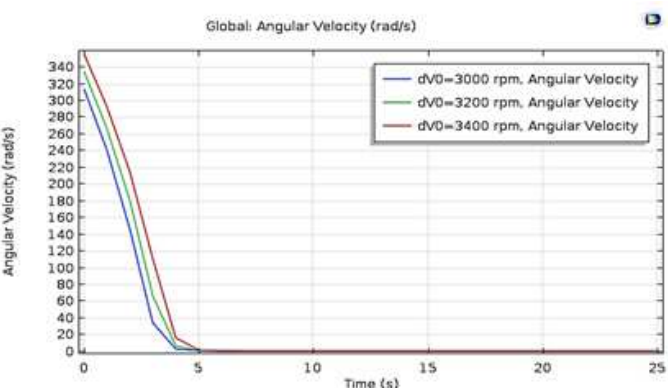

Graph 17 
Graph 16 represents deceleration plot for $\mathrm{Cu}-\mathrm{NdFeB}$ magnet- 6mm air gap -1:5 ratio pulley also from Graph 16, we observe that stopping time obtained from simulation for curves 1500rpm, $1800 \mathrm{rpm}$ and $2100 \mathrm{rpm}$ are close to 3.5, 4 and 4.5 seconds respectively. Graph 17 represents deceleration plot for $\mathrm{Cu}-\mathrm{NdFeB}$ magnet- 6mm air gap-1:2 ratio pulley also from Graph 17, we observe that stopping time obtained from simulation for curves $3000 \mathrm{rpm}$, 3400 rpm and $3800 \mathrm{rpm}$ are close to $3,3.5$ and 4 seconds respectively.

\section{Copper - 3mm dia- NdFeB Magnet - 10mm Air Gap}

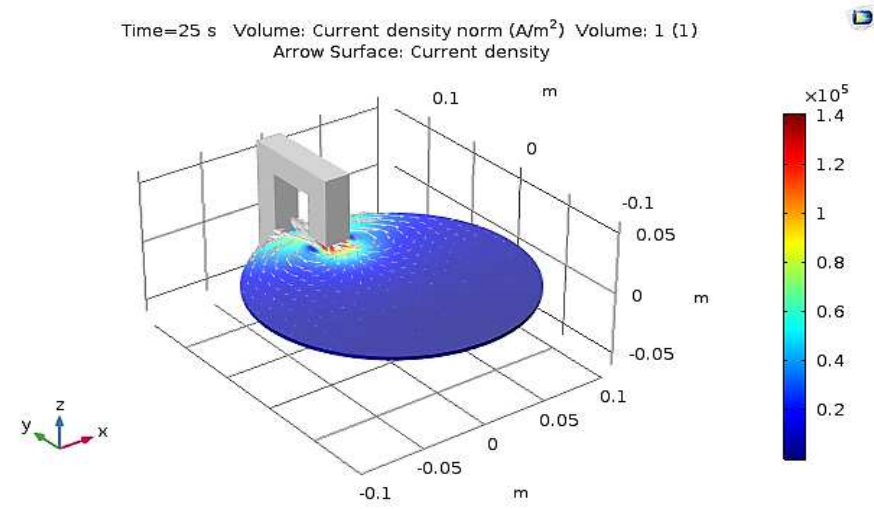

Figure 7: Eddy Current Density Plot for Cu -NdFeB Magnet- 10mm Air Gap

The magnitude of Eddy current density developed is around $1.4 \times 10^{5} \mathrm{~A} / \mathrm{m}^{2}$. Figure 7 also shows the direction of eddy currents induced in the rotating disc which are towards the magnet.

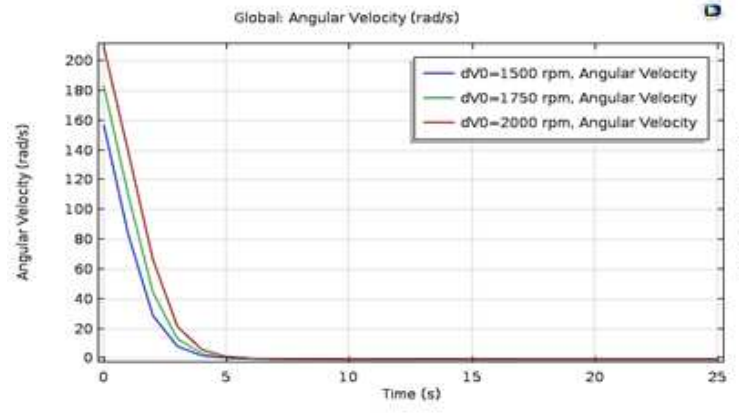

Graph 18

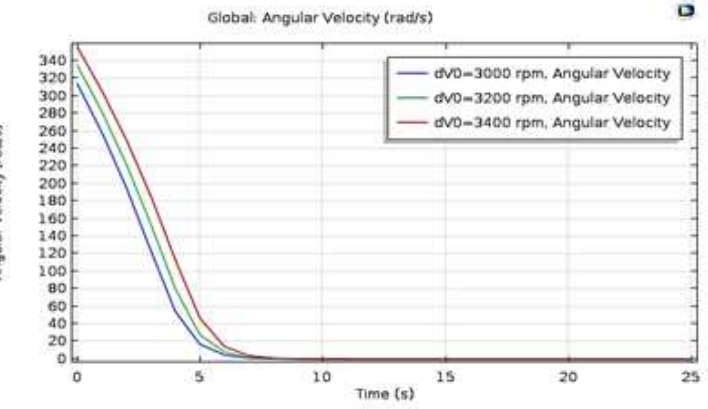

Graph 19

Graph 18 represents deceleration plot for $\mathrm{Cu}-\mathrm{NdFeB}$ magnet- 10mm air gap -1:5 ratio pulley also from graph 18, we observe that stopping time obtained from simulation for curves $1500 \mathrm{rpm}, 1800 \mathrm{rpm}$ and $2100 \mathrm{rpm}$ are close to 4.5, 5.5 and 6 seconds respectively. Graph 19 represents deceleration plot for $\mathrm{Cu}-\mathrm{NdFeB}$ magnet- 10mm air gap-1:2 ratio pulley also from graph 19 , we observe that stopping time obtained from simulation for curves $3000 \mathrm{rpm}, 3400 \mathrm{rpm}$ and $3800 \mathrm{rpm}$ are close to 6,7 and 8 seconds respectively. 


\section{Copper - 3mm dia- Ferrite Magnet - 6mm Air Gap}

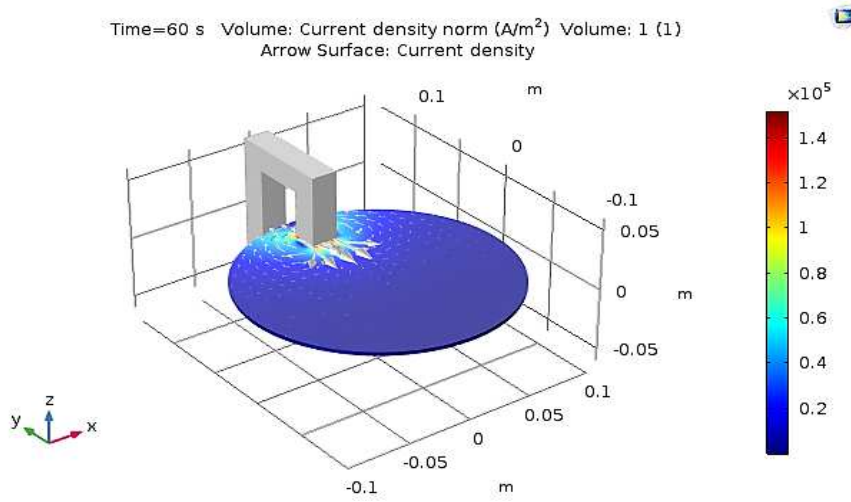

Figure 8: Eddy Current Density Plot for Cu -Ferrite Magnet- 6mm Air Gap

The magnitude of Eddy current density developed is around $1.4 \times 10^{5} \mathrm{~A} / \mathrm{m}^{2}$. Figure 8 also shows the direction of eddy currents induced in the rotating disc which are away from the magnet.

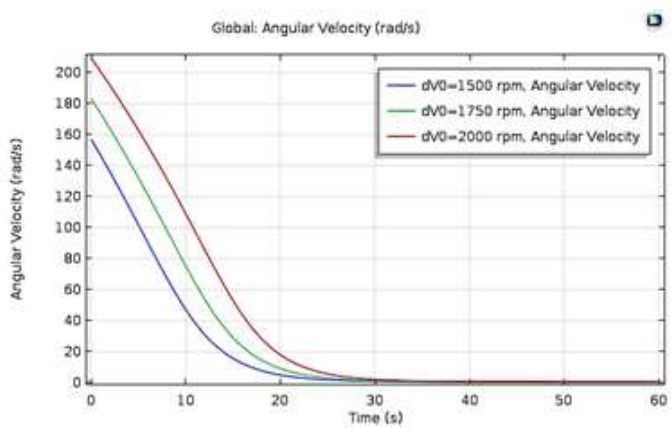

Graph 20

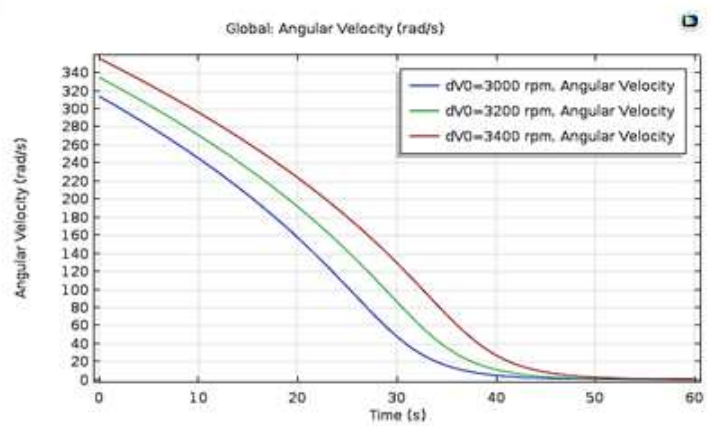

Graph 21

Graph 20 represents deceleration plot for $\mathrm{Cu}$-Ferrite magnet- $6 \mathrm{~mm}$ air gap -1:5 ratio pulley also from Graph 20, we observe that stopping time obtained from simulation for curves $1500 \mathrm{rpm}, 1800 \mathrm{rpm}$ and $2100 \mathrm{rpm}$ are close to 24, 26 and 28 seconds respectively. Graph 21 represents deceleration plot for $\mathrm{Cu}$-Ferrite magnet- 6mm air gap-1:2 ratio pulley also from Graph 21, we observe that stopping time obtained from simulation for curves 3000rpm, $3400 \mathrm{rpm}$ and $3800 \mathrm{rpm}$ are close to 38,42 and 46 seconds respectively.

\section{Copper - 3mm dia- Ferrite Magnet - 10mm Air Gap}

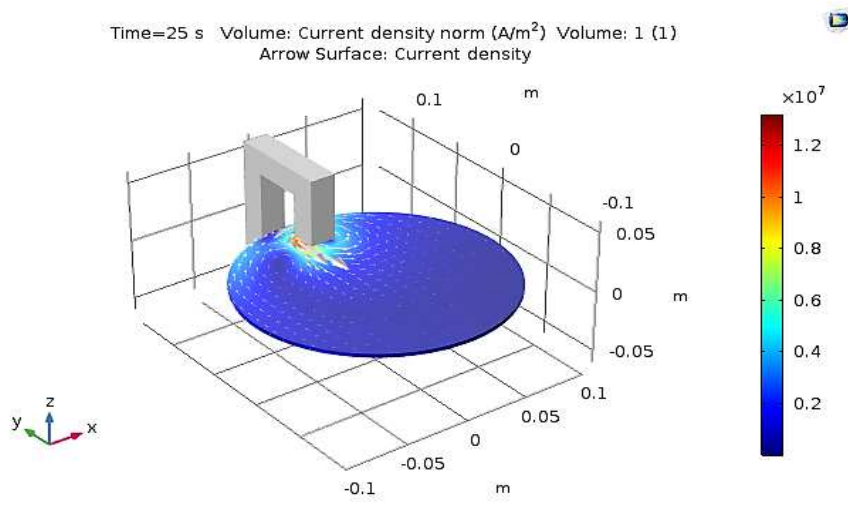

Figure 9: Eddy Current density Plot for Cu -Ferrite Magnet- 10mm Air Gap 


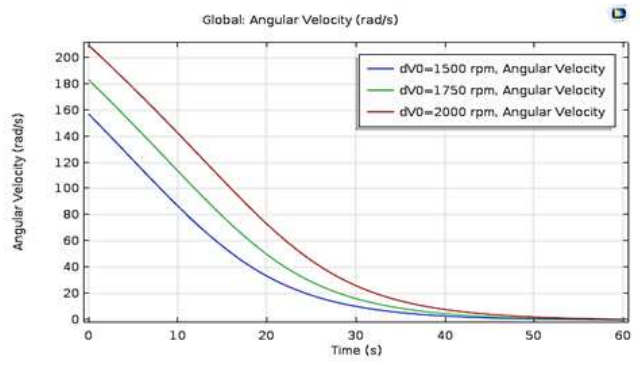

Graph 22

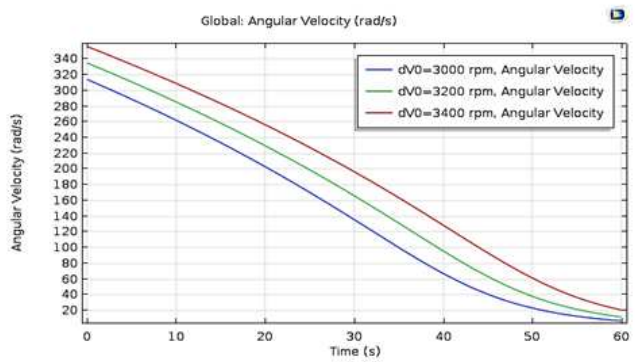

Graph 23

$.2 \times 10^{7} \mathrm{~A} / \mathrm{m}^{2}$. Figure 9 also shows the direction of eddy currents induced in the rotating disc which are away from the magnet. Graph 22 represents deceleration plot for $\mathrm{Cu}$-Ferrite magnet- $10 \mathrm{~mm}$ air gap -1:5 ratio pulley also from Graph 22, we observe that stopping time obtained from simulation for curves $1500 \mathrm{rpm}, 1800 \mathrm{rpm}$ and $2100 \mathrm{rpm}$ are close to 38, 42 and 45 seconds respectively. Graph 23 represents deceleration plot for $\mathrm{Cu}$-Ferrite magnet- 10mm air gap-1:2 ratio pulley also from Graph 23, we observe that stopping time obtained from simulation for curves 3000rpm, $3400 \mathrm{rpm}$ and $3800 \mathrm{rpm}$ are close to 58, 64 and 70 seconds respectively.

\section{CONCLUSIONS}

The purpose of the study was to perform a comparative study of experimental and analysis using COMSOL MULTIPHYSICS software. From experimentation, we found that Aluminum 6061 has greater percentage reduction in braking time compared to copper discs. In permanent magnets, NdFeB magnet (1.3T) induces greater magnetic flux density compared to Ferrite magnet (0.3T). Larger the surface area of magnet, more exposure of disc surface to magnetic flux. In case of air gap, it was found that lesser the air gap; more eddy currents were induced due to less air resistance. According to our experimentation we found that $6 \mathrm{~mm}$ air gap is better compared to $10 \mathrm{~mm}$. It was also observed that, as the rpm decreases eddy currents induced in disc also decreases. Hence the percentage reduction of braking time decreases. Conversely, as the rpm increases eddy currents induced in disc also decreases. Hence the percentage reduction of braking time increases. The same results were obtained during software analysis.

\section{REFERENCES}

1. Oscar Rodrigues, Omkar Taskar, Shrutika Sawardekar, Henderson Clemente, Girish Dalvi, "Design \& Fabrication of Eddy Current Braking System”, International Research Journal of Engineering and Technology (IRJET), Volume: 03 Issue: 04, April-2016.

2. G. Priyandoko, M.Z. Baharom, (2011), "Eddy Current Braking Study for Brake Disc of aluminium, Copper and Zinc”, Regional Engineering Postgraduate Conference (EPC) 2011.

3. Sundaramurthy, A. (2017). Detection and Extraction of Brain Tumor from Magnetic Resonance (MR) Image: Review and Analysis. International Journal of Electrical and Electronics Engineering (IJEEE), 6(3), 1-8.

4. Gigih Priyandoko, M.Z Baharom, (2015), "Eddy current braking experiment using brake disc from Aluminum series of A16061 and A17075"

5. Jo-Yu Wu and Robert Lee, (1997), "The Advantages of Triangular and Tetrahedral Edge Elements for Electromagnetic Modelling with the Finite-Element Method”, IEEE Transactions On Antennas And Propagation, Vol. 45, No. 9, September 1997. 
6. Qashqaei, A., \& ASL, R. G. (2015). Numerical Modeling And Simulation Of Copper Oxide Nanofluids Used In Compact Heat Exchangers. International Journal of Mechanical Engineering, 4 (2), 1, 8.

7. Marc T. Thompson, "Permanent Magnet Electrodynamic Brakes Design Principles and Scaling laws", Worcester Polytechnic.

8. Gigih Priyandoko, M.Z Baharom, (2015), "Air-gap effect on Single Axis Vibration of Electromagnetic Braking Using Eddy Current on Bearing cage”, Advanced Structural Integrity and Vibration Research Group (ASIVR), Faculty of Mechanical Engineering, University Kebangsaan Malaysia, Published on ResearchGate http:// www. Researchgate.net/ publication/273058121

\section{APPENDIX \\ COMPONENTS OF MODEL}

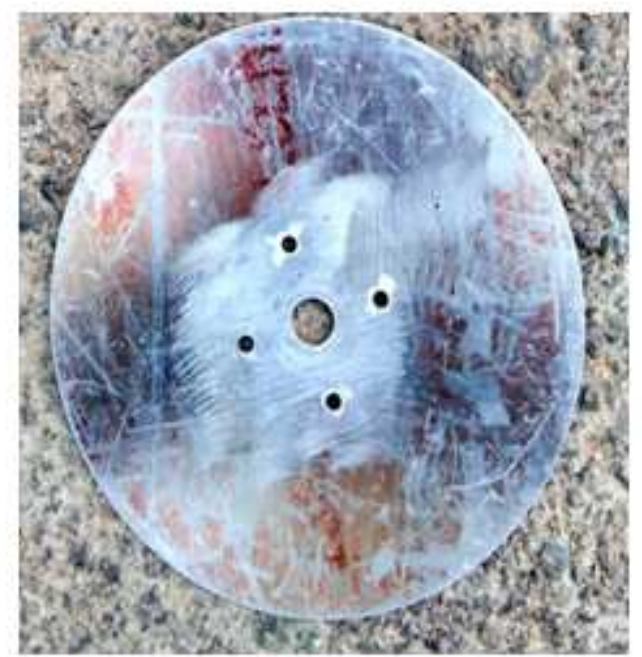

Figure 9: Disc

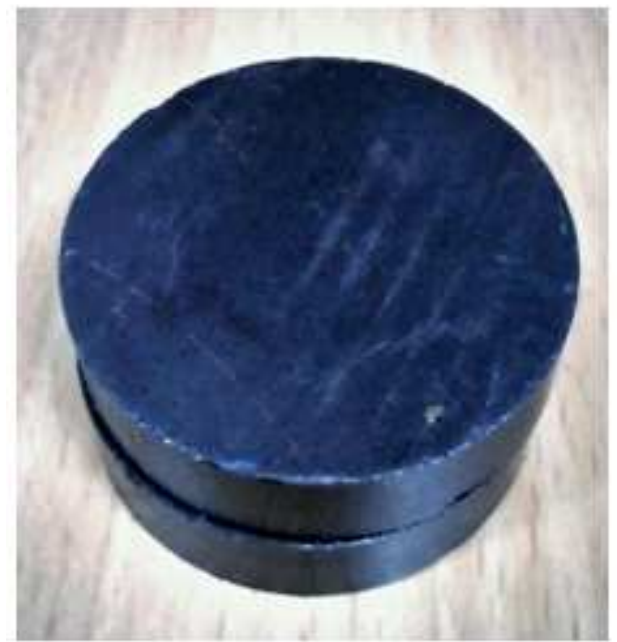

Figure 11: Ferrite

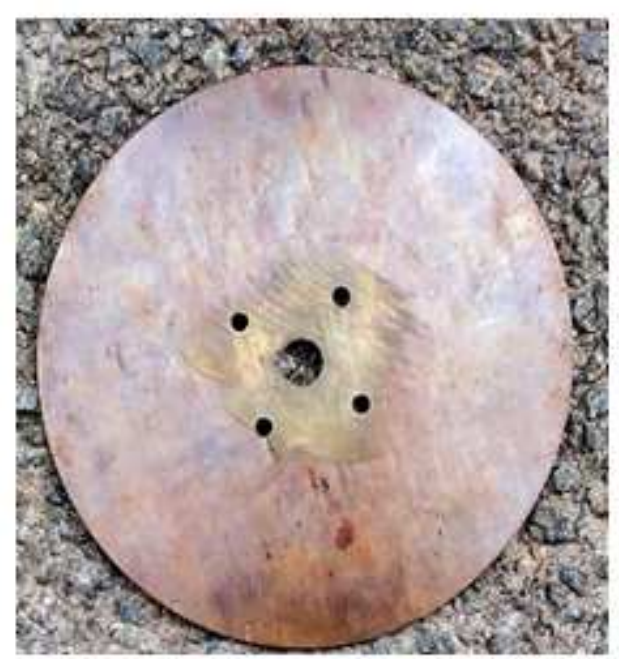

Figure 10: Copper

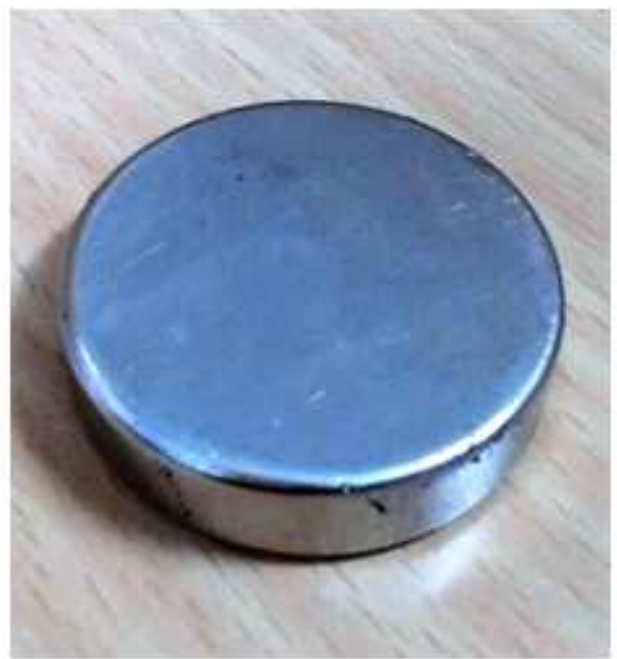

Figure 12: NdFeB 
